\title{
Analisis Cacat Produk Baju Muslim Di Pd. Yarico Collection Menggunakan Metode Failure Mode And Effect Analysis
}

\author{
Isma Masrofah ${ }^{1}$ Hariswan Firdaus $^{2}$ \\ Teknik Industri Universitas Suryakancana \\ Jl. Pasir Gede Raya, Kec. Cianjur, Kab. Cianjur, Jawa Barat 43216 \\ E-mail :Isma.masrofah@unsur.ac.id
}

Dikirimkan:09, 2018. Diterima: 10, 2018. Dipublikasikan: 10, 2018.

\begin{abstract}
Yarico Collection Trad. Co. is a company engaged in clothing convection for the last 12 years. One of the problems faced by this company is the number of defective products that exceed the defect tolerance limits set by the company. The company sets a defect limit of $1 \%$ of the total production, while in the field the number of defects is $3 \%$. This study aims to find out the priorities of the causes of disability and find out how to reduce the number of defects related to women's Muslim clothing that occur in the cutting process of 20 units from 1250 units, the process of sewing or unifying clothes by 22 units out of 1250 units, the process of closing down 19 units out of 1250 unit, and the pressing process is 14 units out of 1250 units. The researcher used the Failure Mode Effects Analysis (FMEA) method to obtain the most dominant failure mode of production process, the calculation of Risk Priority Number (RPN) generated in the pressing process with RPN 504 value, sewing process with $R P N 448$ value, the process of stitching stitches with $R P N$ value 392, and the cutting process with the RPN value 384. From the results of the study obtained several proposals according to the highest RPN value to reduce the number of product defects, including: for cutting defects by adding lighting and periodic machine maintenance, for sewing defects scheduled and the use of components that are standard, for defects in obras are made machine maintenance scheduling, the use of spare parts that are standardized, and using a strongbranded needle, for defects in the pressing process by doing good engine maintenance and providing training to workers with use temperature machine according to the type of fabric.
\end{abstract}

Keywords ; product defect, quality improvement, FMEA, RPN

Abstrak-PD. Yarico Collection merupakan perusahaan yang bergerak dalam bidang konveksi pakaian selama 12 tahun terakhir. Salah satu permasalahan yang dihadapi oleh perusahaan ini yaitu jumlah produk cacat yang melebihi batas tolerasi cacat yang di tetapkan oleh perusahaan. Perusahaan menetapkan batas cacat yaitu $1 \%$ dari jumlah peroduksi sedangkan dilapangan jumlah cacat sebesar $3 \%$. Penelitian bertujuan untuk mengatehaui prioritas penyebab cacat dan mengetahui bagaimana cara menurunkan jumlah cacat terkait baju muslim wanita yang terjadi pada proses cutting sebesar 20 unit dari 1250 unit, proses penjahitan atau penyatuan baju sebesar 22 unit dari 1250 unit, proses obras sebesar 19 unit dari 1250 unit, dan pada proses pressing sebesar 14 unit dari 1250 unit. Peneliti menggunakan metode Failure Modes Efect Analysis (FMEA) sehingga didapat mode kegagalan paling dominan diproses produksi, hasil perhitungan Risk Priority Number (RPN) yang dihasilkan pada proses pressing dengan nilai RPN 504, proses penjahitan dengan nilai RPN 448, proses obras jahitan dengan nilai RPN 392, dan pada proses cutting dengan nilai RPN 384. Dari hasil penelitian didapat beberapa usulan sesuai nilai RPN tertinggi untuk menurunkan jumlah cacat produk, diantaranya : untuk cacat cutting dengan melakukan penambahan penerangan serta melakukan perawatan mesin secara berkala, untuk cacat penjahitan melakukan perawatan mesin secara terjadwal serta penggunaan komponen yang sesuai standard, untuk cacat pada obras dibuat penjadwalan perawatan mesin, penggunaan spare part yang sesuai standar, dan menggunakan jarum obras yeng berbahan kuat, untuk cacat pada proses pressing dengan melakukan perawatan mesin yang baik serta memberika pelatihan kepada pekerja dengan penggunaan suhu mesin sesuai jenis kain.

Kata Kunci : Cacat Produk, Quality Improvement, FMEA, RPN 


\section{PENDAHULUAN}

Era perdagangan bebas sekarang ini menyebabkan penigkatan perekonomian yang sangat pesat dan persaingan sesama pelaku ekonomi juga semakin ketat. Adanya persaingan tersebut memaksa perusahaan mencari berbagai alternatif untuk memenangkan persaingan, mendapatkan profit yang sebesar-besarnya dan memberikan kepuasan kepada pelanggan. Pencapaian tujuan tersebut harus dilakukan tinjauan terhadap proses produksi yang terdapat pada perusahaan, jika dalam proses produksi terdapat masalah, maka yang menjadi indikatornya dilihat dari jumlah cacat yang dihasilkan dalam proses produksi.

Produk cacat merupakan barang yang dibuat dalam proses produksi namun memiliki kekurangan yang menyebabkan nilai kualitas kurang baik. Produk cacat adalah produk yang tidak memenuhi spesifikasi [1]. Hal ini berarti juga tidak sesuai dengan standar kualitas yang telah ditetapkan. Produk cacat yang terjadi selama proses produksi mengacu pada produk yang diterima oleh konsumen. Produk cacat adalah produk yang tidak memenuhi standar kualitas yang ditentukan, tetapi dengan mengeluarkan biaya pengerjaan kembali untuk memperbaikinya, produk tersebut secara ekonomis dapat disempurnakan lagi menjadi produk yang lebih baik lagi [2]. Melihat pentingnya pengendalian kualitas bagi perusahaan, terutama bagi perusahaan konveksi, maka perusahaan perlu memperhatikan kualitas produknya, karena produk yang dihasilkan masih terdapat cacat dan tidak sesuai dengan standar produk.

PD. Yarico Collection yang bergerak di industri konveksi yang memproduksi pakaian jadi terutama baju muslim yang sudah berdiri sejak 12 tahun yang lalu. Kualitas menjadi prioritas utama dalam mempertahankan pelanggan, begitu pula dalam hal penurunan tingkat kegagala peroduksi. Perusahaan ini mempunyai permasalahan pada banyaknya jenis dan jumlah produk cacat yang disebabkan oleh berbagai macam faktor sehingga menyebabkan turunnya kualitas yang berakibat pada kerugian bagi perusahaan karena setiap produk cacat harus mengeluarkan biaya pengerjaan kembali untuk memperbaikinya. Pada setiap proses produksi perusahaan mengalami kecacatan produk diluar batas tolenransi perusahaan yaitu $1 \%$ dari jumlah produksi sedangkan kecacatan produksi sampai 3\%. Dengan meminimalisasi jumlah cacat maka nilai efisiensi mesin dan biaya akan meningkat sehingga upaya untuk mendapatkan keuntungan bagi perusahaan. Berdasarkan latar belakang tersebut, maka perlu suatu cara atau metode yang tepat untuk memecahkan permasalahan yang ada untuk menurunkan tingkat kecacatan produk pada perusahaan. Metode yang dapat digunakan adalah Failure Mode and Effect Analysis (FMEA) yaitu teknik yang digunakan untuk mendefinisikan, mengidentifikasi, dan menghilangkan kegagalan dan masalah pada proses produksi.

\section{A. Kualitas Produk}

Kualitas adalah keseluruhan sifat suatu produk atau pelayanan yang berpengaruh pada kemampuannya untuk memuaskan kebutuhan yang dinyatakan atau tersirat [3]. Produk adalah segala sesuatu yang dapat ditawarkan ke suatu pasar untuk diperhatikan, dimiliki, dipakai atau dikonsumsi sehingga dapat memuaskan keinginan dan kebutuhan [4]. Suatu barang atau jasa dinilai berkualitas apabila dapat memenuhi keinginan konsumen akan nilai produk yang diberikan kepada konsumen. Artinya, mutu atau kualitas merupakan salah satu faktor yang menentukan penilaian kepuasan konsumen.

Produk yang tidak sesuai standard dan mengakibatkan kualitasnya menjadi rendah dan merugikan bagi konsumen dan produsen maka produk tersebut termasuk ke dalam kategori produk cacat dan masih memungkinkan bisa diperbaiki.

\section{B. Fault Tree Analysis (FTA)}

Fault Tree Analysis merupakan sebuah analytical tool yang menerjemahkan secara grafik kombinasi-kombinasi dari kesalahan yang menyebabkan kegagalan dari sistem. Teknik ini berguna untuk mendeskripsikan dan menilai kejadian di dalam system. Metode Fault Tree Analysis ini efektif dalam menemukan inti permasalahan karena memastikan bahwa suatu kejadian 
yang tidak diinginkan atau kerugian yang ditimbulkan tidak berasal pada satu titik kegagalan.

Terdapat 5 tahapan untuk melakukan analisa dengan Fault Tree Analysis (FTA), yaitu sebagai berikut [5]:

- Mendefinisikan masalah dan kondisi batas dari suatu sistem yang ditinjau

- Penggambaran model grafis Fault Tree

- Mencari minimal cut set dari analisa Fault Tree

- Melakukan analisa kualitatif dari Fault Tree

- Melakukan analisa kuantitatif dari Fault Tree

\section{Failure Mode and Effects Analysis (FMEA)}

Failure Mode And Effect Analysis (FMEA) adalah suatu prosedur terstruktur untuk mengidentifikasi dan mencegah sebanyak mungkin mode kegagalan (failure mode). FMEA digunakan untuk mengidentifikasi sumber-sumber dan akar penyebab dari suatu masalah kualitas.

Terdapat dua penggunaan FMEA yaitu dalam bidang desain (FMEA Desain) dan dalam proses (FMEA Proses). FMEA Desain akan membantu menghilangkan kegagalan-kegagalan yang terkait dengan desain, misalnya kegagalan karena kekuatan yang tidak tepat, material yang tidak sesuai, dan lain-lain. FMEA Proses akan menghilangkan kegagalan yang disebabkan oleh perubahan-perubahan dalam variabel proses.

Langkah dalam membuat Tabel FMEA yaitu menulis semua langkah utama proses produksi di PD. Yarico Collection dalam kolom pertama, membuat daftar potensi kesalahan (failure mode) untuk setiap langkah proses produksi, membuat daftar mengenai efek dari failure mode yang ada dalam daftar sebelumnya, menentukan rating pada nilai $\mathrm{S}$ (severity), $\mathrm{O}$ (occurrence), dan (detection). Langkah terakhir adalah mengalikan angka-angka kolom ' $\mathrm{S}$ ' (severity), ' $\mathrm{O}$ ' (occurrence) dan ' $\mathrm{D}$ ' (detection) kemudian hasilnya dimasukan pada kolom 'RPN' (risk priority number). Nilai RPN tertinggi mendapatkan skala prioritas tertinggi untuk dilakukan perbaikan.

TABEL I

\begin{tabular}{|c|c|c|}
\hline \multicolumn{3}{|c|}{ NILAI S (SEVERITY) } \\
\hline Dampak & $\begin{array}{c}\text { Tingkat Keseriusan } \\
\text { Dampak }\end{array}$ & Peringkat \\
\hline $\begin{array}{l}\text { Berbahaya } \\
\text { tanpa } \\
\text { peringatan }\end{array}$ & $\begin{array}{l}\text { Kegagalan tidak didahului } \\
\text { oleh peringatan }\end{array}$ & 10 \\
\hline $\begin{array}{l}\text { Berbahaya } \\
\text { dengan } \\
\text { peringatan }\end{array}$ & $\begin{array}{l}\text { Kegagalan didahului oleh } \\
\text { peringatan }\end{array}$ & 9 \\
\hline $\begin{array}{l}\text { Sangat } \\
\text { tinggi }\end{array}$ & $\begin{array}{l}\text { Produk tidak dapat } \\
\text { dioperasikan }\end{array}$ & 8 \\
\hline Tinggi & $\begin{array}{l}\text { Produk dapat dioperasikan } \\
\text { dengan tingkat kinerja } \\
\text { yang } \\
\text { banyak berkurang }\end{array}$ & 7 \\
\hline Sedang & $\begin{array}{l}\text { Produk dapat dioperasikan } \\
\text { tetapi sebagian item } \\
\text { tambahan } \\
\text { (fungsi sekunder) tidak } \\
\text { dapat berfungsi }\end{array}$ & 6 \\
\hline Rendah & $\begin{array}{l}\text { Produk dapat dioperasikan } \\
\text { dengan tingkat kinerja } \\
\text { yang sedikit berkurang }\end{array}$ & 5 \\
\hline $\begin{array}{l}\text { Sangat } \\
\text { rendah }\end{array}$ & $\begin{array}{l}\text { Cacat disadari oleh } \\
\text { pelanggan }(>75 \%)\end{array}$ & 4 \\
\hline Minor & $\begin{array}{l}\text { Minor Cacat disadari oleh } \\
\text { pelanggan }(50 \%)\end{array}$ & 3 \\
\hline $\begin{array}{l}\text { Sangat } \\
\text { minor }\end{array}$ & $\begin{array}{l}\text { Cacat disadari oleh } \\
\text { pelanggan }(<25 \%)\end{array}$ & 2 \\
\hline Tidak ada & Tidak memiliki pengaruh & 1 \\
\hline
\end{tabular}
Sumber : [6]

TABELII

\begin{tabular}{|c|l|c|}
\hline $\begin{array}{c}\text { Probabilitas } \\
\text { Kejadian } \\
\text { Risiko }\end{array}$ & Frekuensi & Peringkat \\
\hline Sangat Tinggi & $\geq 1$ in 10 & 10 \\
\hline \multirow{3}{*}{ Tinggi } & 1 in 20 & 9 \\
\cline { 2 - 3 } & 1 in 50 & 8 \\
\cline { 2 - 3 } & 1 in 100 & 7 \\
\hline \multirow{3}{*}{ Sedang } & 1 in 500 & 6 \\
\cline { 2 - 3 } & 1 in 2.000 & 5 \\
\cline { 2 - 3 } & 1 in 10.000 & 4 \\
\hline \multirow{2}{*}{ Rendah } & 1 in 100.000 & 3 \\
\cline { 2 - 3 } & 1 in 1.000 .000 & 2 \\
\hline
\end{tabular}




\begin{tabular}{|l|l|l|} 
Sangat rendah & $\begin{array}{l}\text { Kegagalan } \\
\text { dapat } \\
\text { dieliminasi }\end{array}$ & 1 \\
\hline
\end{tabular}

Sumber : [6]

TABEL III

NILAI D (DETECTION)

\begin{tabular}{|c|c|c|}
\hline Deteksi & Kemungkinan Deteksi & Peringkat \\
\hline $\begin{array}{l}\text { Hampir } \\
\text { Tidak } \\
\text { Mungkin }\end{array}$ & $\begin{array}{l}\text { Pengontrol tidak dapat } \\
\text { mendeteksi kegagalan }\end{array}$ & 10 \\
\hline $\begin{array}{l}\text { Sangat } \\
\text { Jarang }\end{array}$ & $\begin{array}{l}\text { Sangat jauh kemungkinan } \\
\text { pengontrol akan } \\
\text { menemukan potensi } \\
\text { kegagalan }\end{array}$ & 9 \\
\hline Jarang & $\begin{array}{l}\text { Jarang kemungkinan } \\
\text { pengontrol akan } \\
\text { menemukan potensi } \\
\text { kegagalan }\end{array}$ & 8 \\
\hline $\begin{array}{l}\text { Sangat } \\
\text { Rendah }\end{array}$ & $\begin{array}{l}\text { Kemungkinan pengontrol } \\
\text { akan menemukan potensi } \\
\text { kegagalan sangat rendah }\end{array}$ & 7 \\
\hline Rendah & $\begin{array}{l}\text { Kemungkinan pengontrol } \\
\text { akan menemukan potensi } \\
\text { kegagalan rendah }\end{array}$ & 6 \\
\hline Sedang & $\begin{array}{l}\text { Kemungkinan pengontrol } \\
\text { akan menemukan potensi } \\
\text { kegagalan sedang }\end{array}$ & 5 \\
\hline $\begin{array}{l}\text { Agak } \\
\text { Tinggi }\end{array}$ & $\begin{array}{l}\text { Kemungkinan pengontrol } \\
\text { akan menemukan potensi } \\
\text { kegagalan agak tinggi }\end{array}$ & 4 \\
\hline Tinggi & $\begin{array}{l}\text { Kemungkinan pengontrol } \\
\text { akan menemukan potensi } \\
\text { kegagalan tinggi }\end{array}$ & 3 \\
\hline $\begin{array}{l}\text { Sangat } \\
\text { Tinggi }\end{array}$ & $\begin{array}{l}\text { Kemungkinan pengontrol } \\
\text { akan menemukan potensi } \\
\text { sangat tinggi }\end{array}$ & 2 \\
\hline $\begin{array}{l}\text { Hampir } \\
\text { Pasti }\end{array}$ & $\begin{array}{l}\text { Kegagalan dalam proses } \\
\text { tidak dapat terjadi karena } \\
\text { telah dicegah melalui } \\
\text { desain solusi }\end{array}$ & 1 \\
\hline
\end{tabular}

\section{Metodologi Penelitian}

Kerangka pemikiran adalah uraian atau pernyataan (proposisi) tentang kerangka konsep pemecahan masalah yang telah diidentifikasi atau dirumuskan dalam penyusun penelitian yang diamati, Alur jalan pikiran secara logis dalam menjawab masalah yang didasarkan pada landasan teoretik dan atau hasil penelitian yang relevan.

Paparan yang harus dilakukan dalam kerangka berpikir adalah perpaduan antara asumsi-asumsi teoretis dan asumsi-asumsi logika dalam menjelaskan atau memunculkan variabel-variabel yang diteliti serta bagaimana kaitan diantara variabel-variabel tersebut, maka dibutuhkan langkah-langkah untuk menguraikan tahapan-tahapan penelitian, pendekatan dan model dari masalah tersebut untuk lebih jelasnya langkah-langkah yang dilakukan dibuat diagram alir atau flow chart seperti pada gambar 1 .

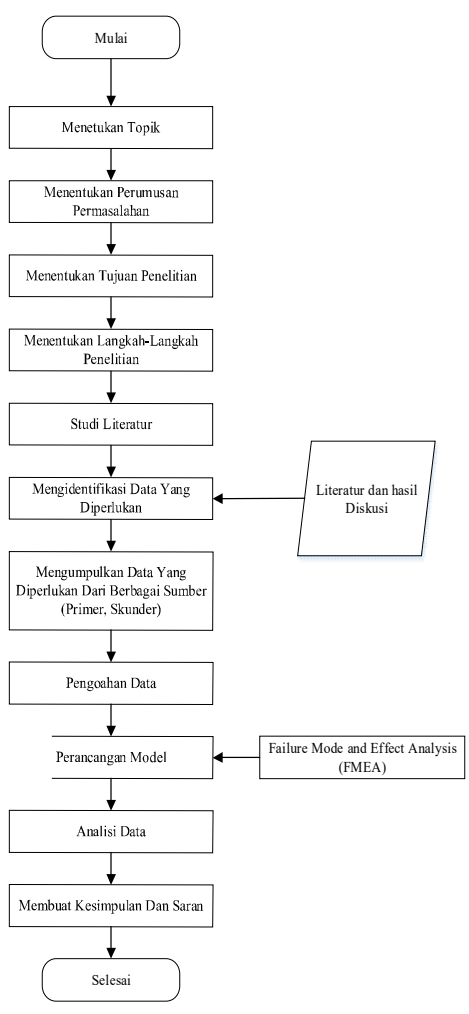

Gambar 1. Kerangka Penelitian

\section{a) Menentukan Topik}

Menentukan topik adalah tahap pertama untuk melakukan penelitian ini, topik apa yang akan diteliti.

\section{b) Menentukan Perumusan Masalah}

Menentuan perumusan masalah adalah mencari masalah apa yang sering terjadi diperusahaan yang akan menjadi tujuan penelitian untuk memecahkan masalah yang terjadi.

\section{c) Menentukan Tujuan Penelitian}

Menentukan tujuan penelitian adalah untuk melakukan penelitian yang bermanfaat bagi perusahan demi kemajuan perusahaan. 


\section{d) Menentukan Langkah-Langkah Penelitian}

Menentukan langkah-langkah penelitian agar penelitian berjalan lancar dan apa saja yang harus di akukan dalam penelitian ini.

e) Studi Literatur

Studi literatur dilakukan dengan tujuan untuk mendapatkan konsep serta metode yang berhubungan dengan masalah yang terjadi dan tujuan penenlitian yang akan di capai.

\section{f) Mengindentifikasi Data Yang Diperlukan}

Mengindentifikasi data yang diperlukan adalah mencari data apa saja yang di perlukan untuk melakukan penelitian ini.

g) Pengumpulan Data

Pengumpulan data yang diperlukan sebagai data yang akan digunakan untuk memecahkan masalah yang dirumuskan sebelumnya. Berikut jenis data dan cara pengumpulan datanya.

TABEL IV

TEKNIK PENGUMPULAN DATA

\begin{tabular}{|l|l|l|l|}
\hline No & \multicolumn{1}{|c|}{$\begin{array}{c}\text { Jenis } \\
\text { Data }\end{array}$} & $\begin{array}{c}\text { Metode } \\
\text { Pengumpulan } \\
\text { Data }\end{array}$ & $\begin{array}{c}\text { Sumber } \\
\text { Data }\end{array}$ \\
\hline 2 & $\begin{array}{l}\text { Data } \\
\text { umum }\end{array}$ & $\begin{array}{l}\text { Wawancara } \\
\text { kegiatan } \\
\text { produksi }\end{array}$ & $\begin{array}{l}\text { Pimpinan } \\
\text { perusahaan }\end{array}$ \\
\hline 3 & $\begin{array}{l}\text { Wata } \\
\text { produksi } \\
\text { dan } \\
\text { jumlah } \\
\text { kecaatan } \\
\text { produk }\end{array}$ & Observasi & $\begin{array}{l}\text { Pimpinan } \\
\text { perusahaan }\end{array}$ \\
\hline
\end{tabular}

h) Pengolahan Data

Setelah data diperoleh maka maka masuk kedalam proses pengolahan data berdasarkan masalah yang akan dibahas.

i) Perancangan Model

Perancangan model adalah menyusun dan mengolah data yang didapat dengan metode yang digunakan adalah Failure Mode and Effect Analysis (FMEA) yaitu teknik yang digunakan untuk mendefinisikan, mengidentifikasi, dan menghilangkan kegagalan dan masalah pada proses produksi yang diketahui mapun yang potensial terjadi, untuk lebih lanjutnya dapat dilihat flow chat perancangan model dapat dilihat digambar

\section{j) Analisis Data}

Setelah perancangan model selesai maka dilakukan analisis data untuk memcari jalan keluar dari permasalahan yang diteliti.

\section{k) Kesimpulan Dan Saran}

Kesimpulan dan saran adalah menyimpulkan hasil dari penelitian ini utuk memperbaiki masalah yang terjadi diperusahaan dan memberikan saran yang sudah diteliti guna memberi keuntungan bagi perusahaan.

\section{HASIL PENELITIAN}

Berdasarkan hasil pengamatan pada Proses Produksi Baju Muslim maka dapat diketahui data-data sebagaimana di sajikan pada tabel V, VI, VII dan VIII.

TABEL V

KLASIFIKASI FUNGSI PROSES PRODUKSI BAJU

\begin{tabular}{|c|c|c|c|}
\hline \multicolumn{4}{|c|}{ MUSLIM } \\
\hline \multirow{2}{*}{$\begin{array}{l}\mathbf{N} \\
\mathbf{0}\end{array}$} & \multirow{2}{*}{$\begin{array}{l}\text { Fungsi } \\
\text { Proses }\end{array}$} & \multicolumn{2}{|c|}{ Klasifikasi } \\
\hline & & $\begin{array}{c}\text { Produk } \\
\text { Baik } \\
\end{array}$ & Produk Gagal \\
\hline 1 & $\begin{array}{l}\text { Pemolaan/ } \\
\text { Desain }\end{array}$ & $\begin{array}{l}\text { Pola sesuai } \\
\text { cetakan } \\
\text { mengikuti } \\
\text { garis pinggir } \\
\text { cetakan. }\end{array}$ & $\begin{array}{l}\text { Pola tidak } \\
\text { sesuai cetakan } \\
\text { atau garis pola } \\
\text { melenceng dari } \\
\text { cetakan. }\end{array}$ \\
\hline 2 & Grading & $\begin{array}{l}\text { Pemberian } \\
\text { ukuran atau } \\
\text { size baju } \\
\text { muslim } \\
\text { sesuai } \\
\text { dengan } \\
\text { sampel. }\end{array}$ & $\begin{array}{l}\text { Ukuran tidak } \\
\text { sesuai dengan } \\
\text { size yang di } \\
\text { perlukan atau } \\
\text { sampel }\end{array}$ \\
\hline \multirow{2}{*}{$\begin{array}{l}\mathbf{N} \\
\mathbf{0}\end{array}$} & \multirow{2}{*}{$\begin{array}{l}\text { Fungsi } \\
\text { Proses }\end{array}$} & \multicolumn{2}{|c|}{ Klasifikasi } \\
\hline & & $\begin{array}{c}\text { Produk } \\
\text { Baik }\end{array}$ & Produk Baik \\
\hline 3 & Cutting & $\begin{array}{l}\text { Pemotonga } \\
\text { n sesuai } \\
\text { dengan pola } \\
\text { atau cetakan. }\end{array}$ & $\begin{array}{l}\text { Pemotongan } \\
\text { tidak sesuai } \\
\text { dengan pola dan } \\
\text { cetakan. }\end{array}$ \\
\hline 4 & $\begin{array}{l}\text { Penjahitan/ } \\
\text { Penyatuan }\end{array}$ & $\begin{array}{l}\text { Jahitan kuat } \\
\text { dan rapi. }\end{array}$ & $\begin{array}{l}\text { Jahitan tidak } \\
\text { kuat dan mudah } \\
\text { lepas. }\end{array}$ \\
\hline 5 & Obras & $\begin{array}{l}\text { Jahitan rapi } \\
\text { dan kuat. }\end{array}$ & $\begin{array}{l}\text { Jahitan tidak } \\
\text { rapi, loncat- } \\
\text { loncat serta } \\
\text { mudah lepas }\end{array}$ \\
\hline
\end{tabular}




\begin{tabular}{|c|l|l|l|}
\hline & & $\begin{array}{l}\text { dari pinggiran } \\
\text { kain baju } \\
\text { muslim. }\end{array}$ \\
\hline 6 & Pressing & $\begin{array}{l}\text { Baju rapi } \\
\text { dan tidak } \\
\text { mengkerut. }\end{array}$ & $\begin{array}{l}\text { Baju } \\
\text { mengkerut dan } \\
\text { bolong karena } \\
\text { terlalu panas } \\
\text { dan lama. }\end{array}$ \\
\hline 7 & Packing & $\begin{array}{l}\text { Baju rapi } \\
\text { didalam } \\
\text { plastik } \\
\text { kemasan. }\end{array}$ & $\begin{array}{l}\text { Baju tidak rapi } \\
\text { di dalam } \\
\text { kemasan. }\end{array}$ \\
\hline
\end{tabular}

TABEL VI

\begin{tabular}{|c|c|}
\hline \multicolumn{2}{|c|}{ JUMLAH PRODUKSI } \\
\hline Produksi \\
\hline Bulan & Jumlah \\
\hline Agustus & 1450 \\
\hline September & 1050 \\
\hline Oktober & 1250 \\
\hline
\end{tabular}

TABEL VII

DATA KEGAGALAN PRODUK

\begin{tabular}{|c|c|c|c|c|c|}
\hline $\begin{array}{c}\text { N } \\
\text { o }\end{array}$ & $\begin{array}{c}\text { Fungsi } \\
\text { Proses }\end{array}$ & $\begin{array}{c}\text { Ag } \\
\text { ust } \\
\text { us }\end{array}$ & $\begin{array}{c}\text { Sept } \\
\text { emb } \\
\text { er }\end{array}$ & $\begin{array}{c}\text { Okto } \\
\text { ber }\end{array}$ & $\begin{array}{c}\text { Rata-Rata } \\
\text { Jumlah } \\
\text { Produksi } \\
\text { Cacat }\end{array}$ \\
\hline 1 & Desain & 36 & 21 & 28 & 28 \\
\hline 2 & $\begin{array}{c}\text { Gradin } \\
g\end{array}$ & 33 & 15 & 24 & 24 \\
\hline 3 & Cutting & 48 & 27 & 39 & 38 \\
\hline 4 & $\begin{array}{c}\text { Penjahit } \\
\text { an }\end{array}$ & 55 & 33 & 44 & 44 \\
\hline 5 & Obras & 42 & 22 & 33 & 32 \\
\hline 6 & $\begin{array}{c}\text { Pressin } \\
g\end{array}$ & 39 & 25 & 34 & 33 \\
\hline 7 & Packing & 38 & 13 & 21 & 24 \\
\hline
\end{tabular}

TABEL VIII

DATA JUMLAH KEGAGALAN

\begin{tabular}{|c|c|c|}
\hline No & Fungsi Proses & Jumlah Kegaglan \\
\hline 1 & Pemolaan/Desain & 28 unit/1250 unit \\
\hline 2 & Grading & 23 unit/1250 unit \\
\hline 3 & Cutting & 38 unit/1250 unit \\
\hline 4 & Penjahitan/Penyatuan & 44 unit/1250 unit \\
\hline 5 & Obras & 32 unit/1250 unit \\
\hline
\end{tabular}

\begin{tabular}{|c|c|c|}
\hline 6 & Pressing & 33 unit/1250 unit \\
\hline 7 & Packing & 24 unit/1250 unit \\
\hline
\end{tabular}

\section{PEMBAHASAN}

Berdasarkan jumlah kegagalan pada proses deteksi, jumlah kegagalan melebihi toleransi yang diberikan oleh perusahaan dan langkah selanjutnya adalah membuat pohon kesalahan (Fault Tree).

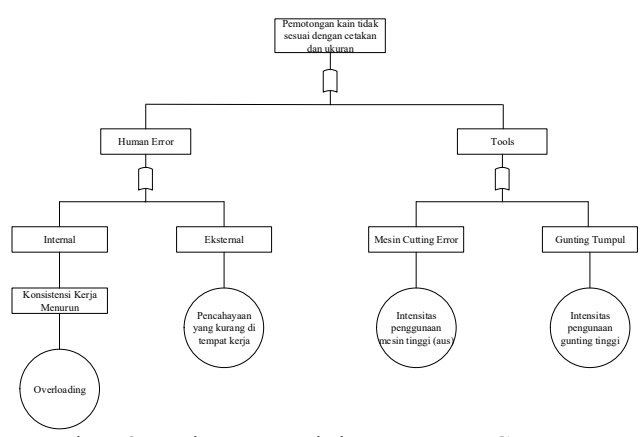

Gambar 2. Pohon Kesalahan Proses Cutting

Penyebab kegagalan pada proses cutting disebabkan oleh 2 faktor yaitu human error dan tools yang digunakan, penyebab yang pertama yaitu kesalahan penempatan penggaris atau cetakan pada kain yang akan dipotong yang disebabkan oleh faktor kelelahan pekerja dan menurunnya kefokusan saat bekerja serta kurangnya penyacahayaan dilingkungan kerja, dan yang kedua adalah yang disebabkan oleh tools atau alat yang digunakan dalam proses cutting seperti mesin cutting yang rusak atau terjadi masalah pada mesin serta gunting yang tumpul yang digunakan dapat mengakibatkan terjadinya kegagalan pada proses cutting atau pemotongan dari gulungan kain menjadi selembaran kain untuk diproses ketahap selanjutnya.

Penyebab kegagalan atau kecacatan produk pada proses penyatuan baju muslim bagi dapan dan belakang baju disebab oleh dau faktor yaitu Human error dan mesin jahit, kegagalan atau defect yang disebabkan oleh Human error terjadi dalam dua jenis yang mempengaruhi kegagalan yaitu dari internal yang mengalami kelelahan dalam bekerja sehingga konsistensi kerja menurun dan yang 
selanjutnya dari eksternal yaitu kurangnya pencahayaan diruangan tempat kerja, faktor yang kedua dari alat yang digunakan atau mesin jahitnya itu sendiri akibat mesin mengalami kerusakan saat digunakan karena kurangnya perawatan pada mesin serta jarum jahit yang tumpul digunakan dengan intensitas tinggi maka akan mengalami kegagalan pada proses penyatuan baju muslim.

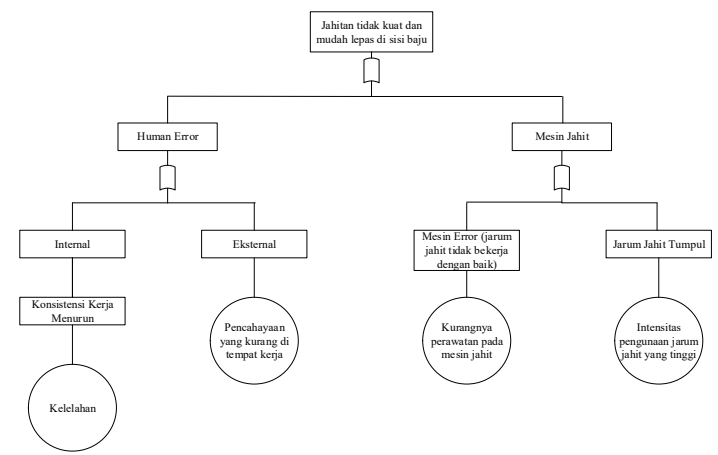

Gambar 3. Pohon Kesalahan Proses Penyatuan Baju

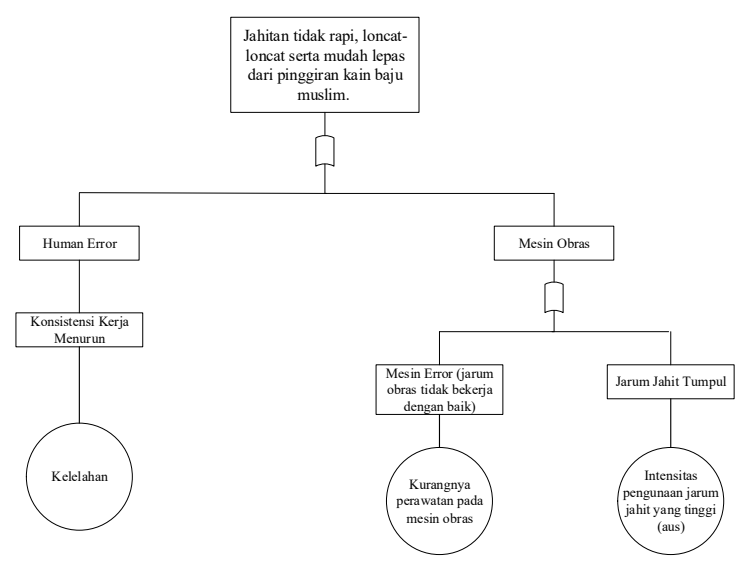

Gambar 4. Pohon Kesalahan Proses Obras

Penyebab kegagalan pada proses obaras terdapat dau faktor yaitu human error dan pada mesin obrasnya sendiri, yang disebebakan oleh manusia karena faktor kelelahan dalam bekerja dan menurunyan kosistensi saat bekerja, yang kedua berasal dari mesin obrasnya itu sendiri yang disebabkan karena mesin obras mengalami kerusakan atau error karena kurangnya perawatan terhadap mesin obras serta jarum yang tumpul menjadi penyebab kegagalan lain saat proses obras.
Faktor yang menyebabkan kegagalan pada proses pressing yang menyebabkan baju menjadi mengkerut atau bolong karena terlalu panas dan lama penyebabnya yaitu dari manusia dan alat yang digunakan, saat menggunakan alat untuk proses pressing kurangnya ketelitian pada penyetelan suhu alat yang bisa menyebabkan terjadinya kegagalan pada proses ini atau mesin pressingnya itu sendiri yang mengalami kerusakan atau suhu tidak stabil karena kurangnya perawatan secara berkala diperusahaan.

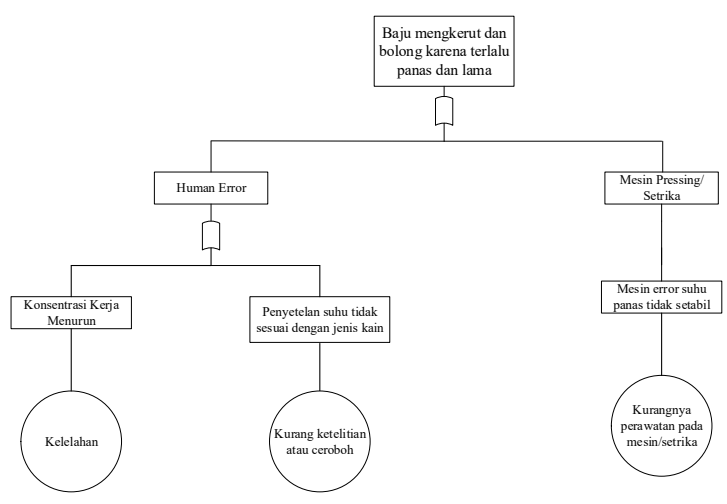

Gambar 5. Pohon Kesalahan Proses Pressing

Failure Mode And Effect Analysis (FMEA) adalah suatu prosedur terstruktur untuk mengidentifikasi dan mencegah sebanyak mungkin mode atau penyebab kegagalan (faikure mode). FMEA digunakan untuk mengidentifikasi sumber-sumber dan akar penyebab dari suatu kualitas, selanjutnya membuat tabel berdasarkan Fault Tree Analysis (FTA) selanjutnya memberi pembobotan pada nilai Saverity, Occurance, dan Detection berdasarkan potensi kegagalan ini untuk menghasilkan Risk Priority Number (RPN). Kegagalan yang menyebabkan kecacatan produk dan perhitungan Rist Priority Number (RPN) dideskripsikan dibawah ini:

1) Kegagalan pemotongan atau cutting yang terjadi diakibatkan dari kesalahan penempatan cetakan pada kain dan mesin yang mengalami masalah karena dengan penggunaan intensitas yang tinggi dan cepat aus serta gunting tumpul tidak tajam karena intensitas pemakaian dan dengan pencahayaan diruangan yang kurang terang, efek dari penyebab kegagalan itu 
pemotongan tidak rapi dan tidak sesuai cetakan yang telah ditentukan. Berdasarkan hal tersebut kegagalan pada proses cutting dibobot nilai:

a. Severity adalah 6, karana akibat yang ditimbulkan dari proses cutting akan berperangaruh terhadap kualitas baju muslim, kain yang mengalami kegagalan pada proses ini akan tetap diproduksi lebih lanjut akan tetapi tidak akan sesuai dengan ukuran.

b. Occurance adalah 8, dilihat langsung dilapangan dimana jumlah kegagalan pada proses cutting berjumlah 38 potongan kain dari 1250 kain yang di potong dan melebihi toleransi dari perusahaan yaitu 13 potong kain dari 1250 kain.

c. Detection adalah 8 , berdasarkan hasil dari lapangan metode pencegahan yang dilakakan belum bisa mengurangi jumlah kegagalan sesuai toleransi yang ditetapkan oleh perusahaan, hasil dari proses detection berada pada rating 8 dalam standar nilai detection.

d. Berdasarkan point di atas a, b, c, bahwa nilai untuk severity adalah 6 , nilai occurance 8, dan nilai detection 8, sehingga nilai Risk Priority Number (RPN) yang diperoleh adalah 384 merupakan hasil perkalian dari antara $\mathrm{S}$, $\mathrm{O}$, dan $\mathrm{D}$ yang dirumuskan $\mathrm{RPN}=\mathrm{S} \mathrm{x}$ $\mathrm{O} \times \mathrm{D}=6 \times 8 \times 8=384$

2) Kegagalan pada proses penyatuan baju muslim yang terjadi diakibatkan dari kesalahan pekerja dan mesin jahitnya, kesalahan dari pekerja yang menyebabkan jahitan tidak rapi karena pada saat menjahit tidak mengikuti garis jahitan serta jahitan terlepas dan tidak kuat diakibatkan oleh mesin jahit yang mengalami kerusakan dan jarum jahit yang tumpul karena intensitas penggunaan yang tinggi. Berdasarkan hal tersebut kegagalan pada proses penyatuan baju muslim diberi bobot nilai:

a. Severity adalah 7, akibat yang ditimbulkan dari proses penyatuan baju muslim sangat berperangaruh terhadap kualitas baju muslim, dan konsumen akan merasakan penurunan kualitas tersebut. b. Occurance adalah 8 , berdasarkan hasil dari lapangan frekuensi kegagalan berjumlah 44 unit dari 1250 unit dan ini menjadi jumlah terbesar kegagalan pada proses pembuatan baju muslim yang disebabkan dari kesalahan penjahit dan mesin yang mengalami masalah, dan jumlah kegagalan pada rating 8 dari nilai occurance.

c. Detection adalah 8, berdasarkan hasil dari lapangan metode pencegahan yang dilakakan belum bisa mengurangi jumlah kegagalan sebesar 22 unit sesuai toleransi yang ditetapkan oleh perusahaan, hasil dari proses detection berada pada rating 8 dalam standar nilai detection.

d. Berdasarkan point di atas a, b, c, bahwa nilai untuk severity adalah 8 , nilai occurance 8, dan nilai detection 8, sehingga nilai Risk Priority Number (RPN) yang diperoleh adalah 448 merupakan hasil perkalian dari antara $\mathrm{S}$, $\mathrm{O}$, dan $\mathrm{D}$ yang dirumuskan $\mathrm{RPN}=\mathrm{S} \times$ $\mathrm{O} \times \mathrm{D}=7 \times 8 \times 8=448$

3) Kegagalan atau kecacatan dalam proses obras sama halnya dengan kegagalan pada proses penjahitan mulai dari faktor maanusia yang mengalami kelelahan dan menururnnya kosentrasi saat bekerja kesalahan penyusunan benang obras serta mesin yang menglami masalah yang menyebabkan jahitan tidak rapi atau tidak menyulam dan benang loncat-loncat dan mudah lepas. Berdasarkan hal tersebut kegagalan pada proses cutting dibobot nilai:

a. Severity adalah 7, karana akibat yang ditimbulkan dari proses obras sangat berperangaruh terhadap kualitas baju muslim, kain mengalami kegagalan dan proses selanjutnya tidak berjalan berakibat kepada kerugian perusahaan.

b. Occurance adalah 8, dilihat langsung dilapangan dimana jumlah kegagalan pada proses cutting berjumlah 32 unit dari 1250 unit berdasarkan data tersebut terjadi keseringan kegagalan obras, disebabkan dari kesalan manusia yang salah saat merangkai benang dan mesin yang mengalami masalah, kain yang di potong dan melebihi toleransi dari 
perusahaan yaitu 13 potong kain dari 1250 kain, dan terdapat rating 8 pada nilai occurance.

c. Detection adalah 7, berdasarkan hasil dari lapangan metode pencegahan yang dilakukan belum bisa mengurangi jumlah kegagalan sesuai toleransi yang ditetapkan oleh perusahaan, hasil dari proses detection berada pada rating 7 dalam standar nilai detection.

d. Berdasarkan point diatas a, b, c, bahwa nilai untuk severity adalah 7 , nilai occurance 8, dan nilai detection 7, sehingga nilai Risk Priority Number (RPN) yang diperoleh adalah 392 merupakan hasil perkalian dari antara $\mathrm{S}$, $\mathrm{O}$, dan $\mathrm{D}$ yang dirumuskan

$\mathrm{RPN}=\mathrm{S} \times \mathrm{O} \times \mathrm{D}=7 \times 8 \times 7=392$

4) Kegagalan pressing yang terjadi diakibatkan dari kesalahan dua faktor yaitu dari faktor manusia dan mesin atau alat yang digunakan kegagalan atau cacat yang dilakukan manusia kurang ketelitian saat saat mengatur suhu panas mesin atau alat dan mesin yang mengalami masalah dengan suhu panas yang tidak stabil. Berdasarkan hal tersebut kegagalan pada proses cutting dibobot nilai:

a. Severity adalah 9, karana akibat yang ditimbulkan dari proses pressing sangat berperangaruh terhadap kualitas baju muslim, kain yang mengalami kegagalan pada proses ini akan tetap diproduksi lebih lanjut akan tetapi tidak akan sesuai dengan ukuran dan akan dijual dengan harga lebih murah yang berakibat kepada kerugian perusahaan.

b. Occurance adalah 8, dilihat langsung dilapangan dimana jumlah kegagalan pada pressing berjumlah 33 unit dari 1250 kain dari tersebut mengalami keseringan krgagalan dan melebihi toleransi dari perusahaan yaitu 13 potong kain dari 1250 kain.

c. Detection adalah 7 , berdasarkan hasil dari lapangan metode pencegahan dan pemeriksaan yang dilakakan masih mungkin terjadi kegagalan dan belum bisa mengurangi jumlah kegagalan sesuai toleransi yang ditetapkan oleh perusahaan, hasil dari proses detection berada pada rating 7 , dalam standar nilai detection.

d. Berdasarkan point di atas a, b, c, bahwa nilai untuk severity adalah 9, nilai occurance 8, dan nilai detection 7 , sehingga nilai Risk Priority Number (RPN) yang diperoleh adalah 504 merupakan hasil perkalian dari antara $\mathrm{S}$, $\mathrm{O}$, dan $\mathrm{D}$ yang dirumuskan

$\mathrm{RPN}=\mathrm{S} \times \mathrm{O} \times \mathrm{D}=9 \times 8 \times 7=504$

Adapun tabel Failure Mode And Effects Analysis (FMEA) Produksi Baju Muslim dan gambar Urutan Risk Priority Number (RPN) Produksi Baju Muslim dapat dilihat pada tabel IV dan gambar 6 pada LAMPIRAN.

Berdasarkan table VI dan gambar 6 didapatkan proses cutting, penjahitan, obras, dan pressing dampak yang ditimbulkan dari keempat proses ini sangat mempengaruhi kualitas baju muslim dengan jumlah cacat yang tinggi yang melebih toleransi dari perusahaan. Hal ini harusnya ada perbaikan berdasarkan penyebab yang telah dianalisis berdasarkan Fault Tree Analysis dan Failure Mode And Effects Analysis.

\section{A. Analisis Cacat dan Penyebab Kecacatan Produk}

Berdasarkan pengolahan data yang telah dilakukan dengan menggunakan metode Fault Tree Analysis (FTA) dan Failure Mode And Effect Analysis (FMEA) dan didapatkan hasil dari Risk Priority Number (RPN) untuk proses pressing sebesar 504 , penjahitan atau penyatuan baju muslim sebesar 448, proses obras sebesar 392, dan proses cutting sebesar 384. Keempat proses tersebut mendapatkan nilai RPN yang tinggi dan merupakan proses utama dalam pembuatan baju muslim, penyebab terjadinya kegagalan diakibatkan dari manusia, mesin, metode, peralatan, dan lingkungan kerja.

Penyebab bersumber pada menurunnya kosentrasi pekerja karena kelelahan serta kurangnya ketelitian pekerja yang mengakibatkan kegagalan terjadi, dan mesin yang mengalami kerusakan dibeberapa bagian komponennya serta alat yang digunakan mengalami masalah atau aus karena intisitas penggunaan yang tinggi.

Sedangkan penyebab yang disebabkan oleh sistem manajemen kualitas yang melekat pada 
proses yang menyebabkan timbulnya kegagalan, dan penyebab kegagalan umum adalah kesalahan dalam pemilihan supplier dimana bahan yang dideli mengalami kecacatan seperti kurang serat dan kain yang bolong-bolong dikarenakan tidak adanya pemeriksaan secara menyeluruh hanya memperhatikan bahan pada sampel kain. Dan pada pemilihan spare part mesin yang bukan orisinil atau bukan standar kualitas mesin itu. Berdasarkan peyebab-peyebab yang terjadi akan berdampak besar pada penurunannya kualitas baju muslim serta keempat proses tersebut berpontesin mengalami kegagalan pada proses selanjutnya dimana keempat proses itu akan diperbaiki mempunyai kegagalan pada tingkat high severity dan potential severity.

\section{Analisis Upaya PD. Yarico Collection Dalam} Penurunan Kecacatan Produk

Upaya yang dilakukan perusahaan dalam penurunan produk cacat adalah dengan melakukan pemeriksaan pada proses produksi atau produknya jika terjadi kerusakan atau terjadinya masalah pada mesin maka dilakukan perbaikan saat itu juga, dari semua yang dilakukan perusahaan dalam penuruan kecacatan produk dirasa belum mampu mengurangi jumalah kecacatan produk yang terjadi dalam proses produksi baju muslim, dan menjadi penyebab kerugian bagi perusahaan karena produku yang cacat dalam proses produksi akan diproduksi ulang dan membutuhakan waktu dan biaya yang lebih. Serta kurangannya pengetahuan pegawai akan kulitas produk yang lebih mementingkan target produksi terpenuhi mengakibatkan kualitas menurun dan akan berdampak pada daya saing perusahaan yang akan menurun hilangnya kepercayaan dari pelanggan akan produk.

\section{B. Analisis Perbaikan Menurut Fault Tree Analysis (FTA) dan Failure Mode and Effect Analysis (FMEA)}

Berdasarkan hasil pengolahan data dan penilaian RPN pada proses pressing, penyatuan baju muslim, obras, dan cutting mendapat nilai kegagalan tertinggi pada proses produksi setelah dianalisis dengan Fault Tree Analysis (FTA) dan Faliure Mode and Effect Analysis (FMEA) sehingga diketahuai masalah yang terjadi untuk dilakukan perbaikan berikut usulan perbaikan pada keempat proses produksi dapat dilihat di table VII pada LAMPIRAN.

\section{KESIMPULAN}

Dari hasil penelitian yang telah dilakukan maka dapat disimpulkan diantaranya sebagai berikut:

1. Penyebab kegagalan paling dominan diproses produksi, hasil perhitungan Risk Priority Number (RPN) adalah pada proses pressing dengan nilai RPN 504

2. Cara menurunkan jumlah produk cacat adalah sebagai berikut:

- penambahannya beberapa fasilitas infrastruktur penunjang kenyamanan saat bekerja.

- Dilakukan pengawasan secara menyeluruh dan berkala.

\section{REFERENSI}

[1] Hansen; Mowen, Akuntansi Manajemen Biaya, 2nd ed. Jakarta: Salemba Empat, 2001.

[2] Mulyadi, Konsep, manfaat, dan Rekayasa. Jakarta: Salemba Empat, 1999.

[3] Philip Kotler, Manajemen Pemasaran, 11th ed. Jakarta, 2005, vol. Jilid II.

[4] Djaslim Saladin, Manajemen Pemasaran. Jakarta: Salemba Empat, 2002.

[5] Dwi Priyanta, Keandalan dan Perawatan. Surabaya: Institut Teknologi Sepuluh November, 2000.

[6] Leonard Nanda; PS Hartanti Lusia; K. Runtuk Johan, "Analisis Risiko Kualitas Produk dalam Proses Produksi Miniatur Bis dengan Metode Failure Mode and Effect Analysis pada Usaha Kecil Menengah Niki Kayoye," vol. 3, 2014. 


\section{LAMPIRAN}

TABEL IX

FAILURE MODE AND EFFECTS ANALYSIS (FMEA) BAJU MUSLIM

\begin{tabular}{|c|c|c|c|c|c|c|c|c|c|c|}
\hline \multirow{2}{*}{$\begin{array}{l}\mathbf{N} \\
\mathbf{0}\end{array}$} & \multirow{2}{*}{$\begin{array}{l}\text { Deskri } \\
\text { psi } \\
\text { Proses }\end{array}$} & \multirow[b]{2}{*}{$\begin{array}{c}\text { Mode } \\
\text { Kegagalan }\end{array}$} & \multicolumn{2}{|c|}{ Potensi Efek Kegagalan } & \multirow[b]{2}{*}{$\mathbf{S}$} & \multirow[b]{2}{*}{$\begin{array}{l}\text { Penyebab Potensi } \\
\text { Kegagalan }\end{array}$} & \multirow[b]{2}{*}{$\mathbf{O}$} & \multirow[b]{2}{*}{$\begin{array}{c}\text { Proses Kontrol Saat } \\
\text { Ini }\end{array}$} & \multirow[b]{2}{*}{ D } & \multirow[b]{2}{*}{ RPN } \\
\hline & & & $\begin{array}{c}\text { Proses } \\
\text { Berikutnya }\end{array}$ & $\begin{array}{c}\text { Performansi } \\
\text { Produk }\end{array}$ & & & & & & \\
\hline 1 & $\begin{array}{l}\text { Proses } \\
\text { Cutting }\end{array}$ & $\begin{array}{l}\text { Pemotongan kain } \\
\text { tidak sesuai } \\
\text { dengan cetakan } \\
\text { atau ukuran }\end{array}$ & $\begin{array}{l}\text { Proses } \\
\text { penyatuan atau } \\
\text { penjahitan } \\
\text { tertunda } \\
\text { pengerjaannya }\end{array}$ & $\begin{array}{l}\text { Kain yang } \\
\text { defect tidak bisa di } \\
\text { produksi karena } \\
\text { ukuran dan standar } \\
\text { tidak sesuai }\end{array}$ & 6 & $\begin{array}{l}\text { Human error: kesalahan } \\
\text { penempatan cetakan pada } \\
\text { kain } \\
\text { Tools: mesin error } \\
\text { intensitas pekaian tinggi } \\
\text { dan cepat aus serta } \\
\text { gunting tumpul karena } \\
\text { intensitas pemakaian }\end{array}$ & 8 & $\begin{array}{l}\text { Pengawasan terhadap } \\
\text { pekerja dan alat jika } \\
\text { mengalami kerusakan } \\
\text { atau tumpul pada } \\
\text { tools (mesin dan } \\
\text { gunting) diperiksa }\end{array}$ & 8 & 384 \\
\hline 2 & $\begin{array}{l}\text { Proses } \\
\text { Penyata } \\
\text { uan } \\
\text { Baju } \\
\text { Muslim }\end{array}$ & $\begin{array}{l}\text { Jahitan tidak } \\
\text { kuat, rapi, dan } \\
\text { mudah lepas }\end{array}$ & $\begin{array}{l}\text { Proses obras } \\
\text { tidak bisa } \\
\text { berjalan atau } \\
\text { tertunda }\end{array}$ & $\begin{array}{l}\text { Jahitan tidak sesuai } \\
\text { lurus atau tidak } \\
\text { mengkuti alur }\end{array}$ & 7 & $\begin{array}{l}\text { Kesalahan penjahitan } \\
\text { baju muslim yang } \\
\text { disebabkan karena } \\
\text { pekerjanya mengalami } \\
\text { kelelahan serat kosentrasi } \\
\text { yang menurun dan mesin } \\
\text { yang mengalamai } \\
\text { masalah }\end{array}$ & 8 & $\begin{array}{l}\text { Pemeriksaan bagian } \\
\text { baju muslim sebelum } \\
\text { dijahit dan memeriksa } \\
\text { mesin jika mengalami } \\
\text { kerusakan }\end{array}$ & 8 & 448 \\
\hline 3 & $\begin{array}{l}\text { Proses } \\
\text { Obras }\end{array}$ & $\begin{array}{l}\text { Obras tidak rapi, } \\
\text { loncat-loncat dan } \\
\text { mudah lepas }\end{array}$ & $\begin{array}{l}\text { Proses } \\
\text { selanjutnya } \\
\text { tidak berjalan } \\
\text { yaitu proses } \\
\text { pressing } \\
\end{array}$ & $\begin{array}{l}\text { Obras tidak } \\
\text { menganyam dengan } \\
\text { baik dan rapi }\end{array}$ & 7 & $\begin{array}{l}\text { Kesalahan pada } \\
\text { pemasangan benang yang } \\
\text { kurangnya ketelitian dan } \\
\text { serta kosentrasi yang } \\
\text { menurun }\end{array}$ & 8 & $\begin{array}{l}\text { Pemeriksaan pada } \\
\text { kain, benang, dan } \\
\text { mesin jika mengalami } \\
\text { kerusakan atau } \\
\text { masalah }\end{array}$ & 7 & 392 \\
\hline 4 & $\begin{array}{l}\text { Proses } \\
\text { Pressin } \\
\mathrm{g}\end{array}$ & $\begin{array}{l}\text { Kain sobek atau } \\
\text { bolong akibat } \\
\text { terlalu panas }\end{array}$ & $\begin{array}{l}\text { Proses } \\
\text { pengemasan } \\
\text { atau packing } \\
\text { terhenti }\end{array}$ & $\begin{array}{l}\text { Kain mengkerut dan } \\
\text { bolong }\end{array}$ & 9 & $\begin{array}{l}\text { Kesalahan dalam } \\
\text { penyetelan suhu panas } \\
\text { dan terlalu lama pressing }\end{array}$ & 8 & $\begin{array}{l}\text { Diberikannya arahan } \\
\text { mengenai penyetelan } \\
\text { suhu dan waktu } \\
\text { pressing yang di } \\
\text { butuhkan }\end{array}$ & 7 & 504 \\
\hline
\end{tabular}




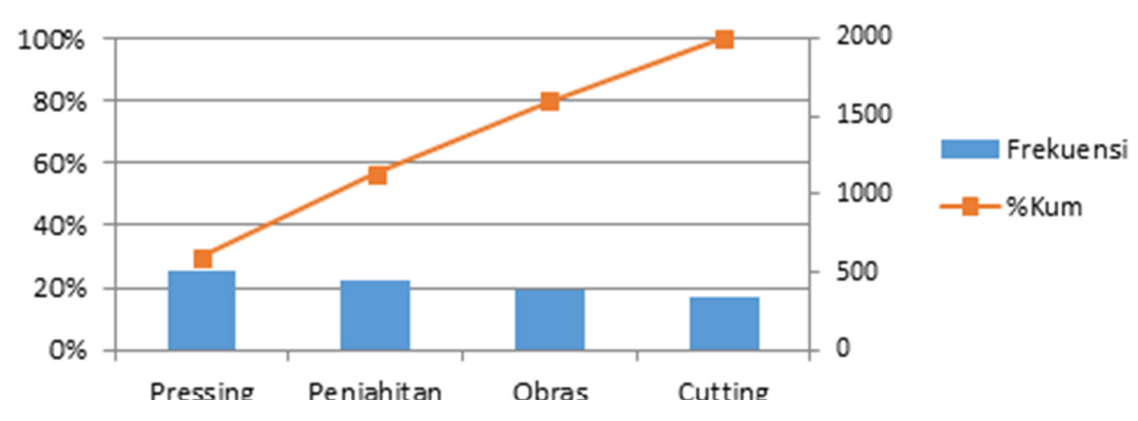

Gambar 6. Risk Priority Number (RPN) Produksi Baju Muslim

TABEL X

USULAN PERBAIKAN

\begin{tabular}{|c|c|c|c|}
\hline No & Proses & Penyebab Kegagalan & Usulan Perbaikan \\
\hline \multirow[t]{2}{*}{1} & \multirow{2}{*}{ Pressing } & Mesin press terlalu panas & $\begin{array}{l}\text { Memberikan pelatihan dan arahan terhadap penyetelan suhu mesin } \\
\text { press sesuai dengan jenis kainya. }\end{array}$ \\
\hline & & $\begin{array}{l}\text { Mesin press eror suhu tidak sesuai setingan yang } \\
\text { di lakukan }\end{array}$ & $\begin{array}{l}\text { Perawatan mesin secara berkala dan melukan pengecekan setiap } \\
\text { akan digunakan. }\end{array}$ \\
\hline \multirow{3}{*}{2} & \multirow{3}{*}{$\begin{array}{l}\text { Penyatuan } \\
\text { Baju/Penjahitan }\end{array}$} & $\begin{array}{l}\text { Lingkungan kerja kurang nyaman dengan } \\
\text { kurangnya pencahayaan dan kurangnya } \\
\text { konsentrasi pekerja }\end{array}$ & $\begin{array}{l}\text { Perlunya ditambahkan pencahayaan serta penambahan pasilitas } \\
\text { kipas angin agar pekerja merasa nyaman saat bekerja. }\end{array}$ \\
\hline & & Mesin jahit yang mengalami kerusakan & $\begin{array}{l}\text { Perawatan mesin harus dilakukan secara berkala dan terjadwal serta } \\
\text { penggunaan komponen yang orisinil agar ketahanan mesin lebih } \\
\text { lama untuk digunakan. }\end{array}$ \\
\hline & & Jarum jahit yang tumpul & $\begin{array}{l}\text { Penggunaan jarum jahit dari bahan yang kuat, serta dilakukan } \\
\text { pemeriksaan pada jarum jahit secara berkala sebelum tumpul atau } \\
\text { aus. }\end{array}$ \\
\hline 3 & Obras & Rangkaian benang yang tidak sesuai & $\begin{array}{l}\text { Melakukan pengawasan serta di cek kembali rangkaian benang } \\
\text { sebelum melakukan obras. }\end{array}$ \\
\hline
\end{tabular}




\begin{tabular}{|c|l|l|l|} 
& Jarum obras tumpul & $\begin{array}{l}\text { Harus dilakukan pemeriksaan secara berkala terhadap jarum obras } \\
\text { dan menggantinya dengan kualitas yang bagus agar bisa bertahan } \\
\text { lebih lama dalam penggunaanya. }\end{array}$ \\
\cline { 3 - 4 } & Mesin obras eror & $\begin{array}{l}\text { Pemerika mesin obras secara berkala dan adanya jadwal perawatan } \\
\text { mesin obras. }\end{array}$ \\
\hline \multirow{4}{*}{ Cutting } & Kurang pencahayaan diruang produksi & $\begin{array}{l}\text { Mengganti bola lampu dengan keterangan lebih besar atau } \\
\text { membuat jendela yang cukup agar sinar matahari dapat membantu } \\
\text { penerangan saat proses produksi. }\end{array}$ \\
\cline { 3 - 4 } & Garis pola yang tidak sesuai cetakan & $\begin{array}{l}\text { Memeriksa kembali garis pola atau tanda untuk memastikan garis } \\
\text { pola tidak ada yang salah sebelum melakukan pemotongan dengan } \\
\text { mesin cutting atau dengan gunting. }\end{array}$ \\
\cline { 3 - 4 } & $\begin{array}{l}\text { Mesin cutting yang mengalami kerusakan atau } \\
\text { gunting tumpul }\end{array}$ & $\begin{array}{l}\text { Melakukan perawatan terhadap mesin cutting dan menggunakan } \\
\text { spare part yang sesuai dengan yang aslinya. }\end{array}$ \\
\hline
\end{tabular}

